\title{
Autonomia e autoria em sala de aula com oficinas de estudos
}

\author{
Autonomy and authorship in the classroom with study workshops \\ Enrique Sérgio Blanco ${ }^{1 *}$, Maria dos Remédios Lima Silva ${ }^{1}$, Larissa Liss Cardoso de Andrade, \\ Bettina Steren dos Santos ${ }^{1}$
}

\begin{abstract}
RESUMO
O presente artigo descreve o uso de uma metodologia ativa de ensino e de aprendizagem em salas de aula da Educação Básica. Este trabalho propõe uma reflexão acerca da metodologia de aprendizagem ativa do tipo oficina de estudos, especificamente a partir da estratégia definida como "Aula Leve". A metodologia utilizada neste artigo é qualitativa, de caráter exploratório e interpretativo. Conforme análises de indicadores teóricos e práticos desta experiência, professores e alunos reconhecem os benefícios para o ensino e a aprendizagem da prática de oficinas de estudos definida como "Aula Leve". Devido às suas características, a metodologia ativa analisada contribui para o desenvolvimento da autonomia e autoria de estudantes do Ensino Fundamental e do Ensino Médio, tornando-os sujeitos ativos de sua aprendizagem.
\end{abstract}

Palavras-chave: Oficinas de estudo; "Aula Leve"; Autonomia; Autoria

\begin{abstract}
This paper describes the experience of an active teaching and learning methodology developed in Basic Education. It is proposed a reflection a reflection concerning a specific kind of active learning methodology known as study workshop, starting from a strategy defined as "Light Class". The approach that has been used is qualitative and of an exploratory and interpretive nature. After analyzing the theoretical and practical indicators of this study, it was found that the practice of study workshops through the "Light Class" strategy has been recognized by teachers and students as a methodology that has benefits to teaching and learning. Due to its features, it was found that the active methodology analysed contributes to the development of autonomy and authorship of Primary and Secondary Education students, turning them active subjects of their learning.
\end{abstract}

Keywords: Study workshop; "Light Class"; Autonomy; Authorship.

\footnotetext{
${ }^{1}$ Pontifícia Universidade Católica do Rio Grande do Sul

*E-mail: enrique.blanco@acad.pucrs.br
} 


\section{INTRODUÇÃO}

As práticas da leitura, interpretação e produção textual são utilizadas tanto na Educação Básica como na Superior e exigem dos estudantes a construção de diversas habilidades que são desenvolvidas com esforço e muita prática em relação à linguagem escrita. Tais competências são essenciais, não apenas para as áreas da comunicação e expressão, mas para a trajetória formativa de todo estudante que busca ser capaz de ler o mundo e pensar criticamente. Diante deste cenário, entre as estratégias para a promoção da motivação na área da leitura, interpretação e produção textual, estão as metodologias ativas de aprendizagem. Utiliza-se a expressão "metodologias ativas de aprendizagem", e não apenas "metodologias ativas", para salientar o sentido educacional inovador de aplicação destas metodologias ao enfatizar a aprendizagem (foco no estudante) e não o ensino (foco no docente). Considera-se a participação ativa do docente, mas é ressaltado o protagonismo do estudante no processo de ensino e de aprendizagem, sendo o foco sua participação ativa, motivada pela intencionalidade e mediação docente (ANTUNES; NASCIMENTO; QUEIROZ, 2019; BERBEL, 2011).

Desse modo, neste artigo, considera-se uma metodologia de aprendizagem como ativa quando promove o protagonismo e a autonomia dos estudantes, tendo um caráter eminentemente construtivista, por implicar o aprender a aprender enquanto construção ativa do sujeito. As práticas decorrentes dessas metodologias encontram eco no sujeito aprendente por estarem contextualizadas à vida real e promoverem significados para os estudantes. Essa proposta vai ao encontro das Diretrizes Curriculares Nacionais da Educação Básica (DCNs), quando ressaltam a importância de selecionar saberes que sejam: “[...] significativos, capazes de se conectarem aos que o estudante já tenha apreendido e que, além disso, tenham sentido para ele, toquem-no intensamente". (BRASIL, 2013, p. 181). Assim, compreende-se que, ao se trabalhar com a prática da leitura, interpretação e escrita em sala de aula por meio de metodologias ativas, contribuise para o desenvolvimento da dimensão da autonomia e autoria dos estudantes. A proposta deste artigo é analisar a metodologia de aprendizagem ativa do tipo oficina de estudos, especificamente a partir da estratégia denominada de "Aula Leve", criada por Fábio Mendes, professor do Instituto Federal de Educação e Tecnologia Sul-RioGrandense. 


\section{APORTE TEÓRICO: INTERPRETAR É LER O MUNDO}

Para que o desenvolvimento da autonomia e da autoria implique a transformação do sujeito aprendente, os processos de ensino e de aprendizagem devem estar fundamentados no protagonismo do estudante; diferentemente do que ocorre com metodologias tradicionais, que dão preferência à transmissão de conteúdos, muitas vezes, dissociados do cotidiano dos estudantes. Pensando no contexto de sala de aula, um dos grandes desafios enfrentados é a leitura de textos, tanto para professores, na perspectiva do ensino, como para estudantes, do ponto de vista da aprendizagem. Na maior parte das vezes, ao se defrontar com um texto, os estudantes conseguem efetivar a leitura, mas não atingem os níveis exigidos de interpretação. De acordo com a Base Nacional Comum Curricular (BNCC), os estudantes do Ensino Médio devem desenvolver competências associadas ao aprofundamento da análise sobre "a perspectiva analítica e crítica da leitura, escuta e produção de textos verbais e multissemióticos", de modo que possam ampliar a “compreensão crítica e intervenção na realidade e de participação social dos jovens, nos âmbitos da cidadania, do trabalho e dos estudos" (BRASIL, 2017, p. 498). As competências citadas são específicas para a Área de Linguagens e suas Tecnologias no Ensino Médio, e os estudantes deverão tê-las desenvolvido ao final desta etapa da Educação Básica. Tais competências estão relacionadas não apenas com uma dimensão técnica, mas com a capacidade de o jovem fazer a leitura do mundo, tal como Freire enfatiza.

A leitura do mundo, segundo o autor, está associada diretamente à interpretação dos contextos nos quais estamos inseridos: "Linguagem e realidade se prendem dinamicamente. A compreensão do texto a ser alcançada por sua leitura crítica implica a percepção das relações entre o texto e o contexto" (FREIRE, 1998, p. 9). Ou seja, para o autor, o ato de ler o mundo traz diversas implicações que impelem o sujeito a interagir e interferir na sociedade, enquanto processo constante de construção e reconstrução, centrado na compreensão do mundo: "Ler é procurar buscar criar a compreensão do lido; daí, entre outros pontos fundamentais, a importância do ensino correto da leitura e da escrita" (FREIRE, 1997, p. 20). A capacidade de o estudante ler o mundo está relacionada com sua autonomia de desenvolver esse processo, associada à construção e reconstrução de significados e compreensões, uma "experiência criativa em torno da compreensão" (FREIRE, 1997, p. 20). Essa experiência depende da prática de ensino e da escrita, de 
acordo com Freire. Deve-se ressaltar que autonomia significa "o direito de dirigir-se e governar-se por suas próprias leis ou regras: independência”. (CHAUÍ, 2002, p. 344).

Portanto, esse sentido de independência, relacionado aos processos de ensino e aprendizagem, vincula-se à capacidade de o estudante desenvolver suas próprias interpretações e compreensões acerca da realidade - leitura de mundo - de forma autônoma. No que diz respeito às práticas propostas pelos processos de ensino e de aprendizagem associados às práticas da escrita e da leitura, deve-se promover condições para que os estudantes desenvolvam os requisitos necessários para se autodeterminar. Por isso, se faz tão necessário contextualizar essas questões à luz do pensamento de Freire (2019), que se refere à autonomia como obra humana, enquanto construção cultural e educativa resultante da interação entre as pessoas e mediada pelo conhecimento. $\mathrm{O}$ ensino e a aprendizagem são aspectos fundamentais nesse processo: “[...] ensinar não é transferir conhecimento, mas criar as possibilidades para a sua produção ou a sua construção" (FREIRE, 2019, p. 47). De acordo com Freire, o conceito de autonomia perpassa todo processo educacional, a fim de que o ser humano possa encontrar seu protagonismo, "O respeito à autonomia e à dignidade de cada um é um imperativo ético e não um favor que podemos ou não conceder uns aos outros”. (FREIRE, 2019, p. 58). Percebe-se, ainda, a ênfase dada por Freire à autonomia como construção propiciada pelo encontro entre educador e educando. O docente deve ter atenção ao fato de que "Ensinar exige respeito à autonomia do ser do educando" e "Saber que devo respeito à autonomia e à identidade do educando exige de mim uma prática em tudo coerente com este saber" (FREIRE, 2019, p.34).

Para que o estudante se compreenda como um ser social, deve-se respeitar sua autonomia, o que implica construir contextos propícios para que ele possa exercê-la. Uma vez que a autonomia não é algo que pode ser concedido pelo professor, mas que deve ser desenvolvido pelo próprio estudante, deve haver as condições para que esse processo ocorra. Nessa perspectiva, como pensar a autoria no contexto escolar? Pode-se encontrar autoria em ideias pronunciadas, em processos inacabados, em textos em construção e até em relação ao ensino, como diz Freire ao ressaltar que "Ensinar exige consciência do inacabamento" (FREIRE, 2019, p. 21). Nesse sentido, observa Vicente Zatti, em "Autonomia e Educação em Immanuel Kant e Paulo Freire": "O homem é inacabado e possui consciência de seu inacabamento, isso é importante para que ele se torne autônomo" (ZATTI, 2007, p. 53). Portanto, o exercício da autonomia implica consciência 
sobre o próprio processo de seu desenvolvimento. No entanto, ser autor de si mesmo reflete a autonomia de se autoconstruir, mas não de forma individualista e solipsista, mas em relação com o outro. Construção que faça sentido, conforme enfatiza Orlandi:

[...] autoria é a produção de um gesto de interpretação, ou seja, na função autor o sujeito é responsável pelo sentido do que diz, em outras palavras, ele é responsável por uma formulação que faz sentido. $\mathrm{O}$ modo como ele faz isso é que caracteriza a sua autoria. Como, naquilo que lhe faz sentido, ele faz sentido. Como ele interpreta o que interpreta. (ORLANDI, 2007, p. 97).

Assim, compreende-se que a autoria no contexto escolar está diretamente associada à autonomia enquanto processo constante de construção e reconstrução de si e do outro, que ocorre em contextos interpretativos mediados pelo ensino e aprendizagem - autoaprendizagem. Autonomia em relação a si, que se efetiva com a presença e participação ativa do outro, compartilhando o mesmo espaço-tempo da sala de aula.

\section{“AULA LEVE": CONTEXTUALIZAÇÃO}

A possibilidade de se trabalhar com metodologias ativas em sala de aula contribui para o desenvolvimento dos processos de ensino e de aprendizagem. Saber como estudar e, ao mesmo tempo, como ensinar pode proporcionar resultados efetivos na aprendizagem dos estudantes. A estratégia "Aula Leve", desenvolvida pelo professor Fábio Mendes (MENDES, 2012), busca estabelecer um caminho claro e objetivo para que estudantes possam desenvolver processos de estudo mais efetivos, tendo a prática da leitura, escrita e interpretação como eixos norteadores. Mendes construiu um método para melhorar a eficácia de seu próprio estudo, obtendo resultados relevantes também para os estudantes que passaram a participar de seus cursos livres. Assim, Mendes elaborou a metodologia ativa de aprendizagem do tipo oficina de estudos, nomeada como "Aula Leve", que é acessível a qualquer contexto escolar e se baseia em quatro etapas (MENDES, 2012), como apresenta o quadro 1.

Quadro 1 - Etapas da "Aula Leve"

\begin{tabular}{|l|l|}
\hline \multicolumn{1}{|c|}{ Etapa } & \multicolumn{1}{c|}{ Descrição das atividades } \\
\hline Leitura panorâmica & leitura rápida, reconhecimento do texto \\
\hline Seleção e marcação & seleção de trechos; sublinha das partes mais significativas \\
\hline
\end{tabular}




\begin{tabular}{|l|l|}
\hline Anotações & registro de informações e relações mais relevantes \\
\hline Exercícios e debates & $\begin{array}{l}\text { elaboração de questões, utilização de questões prontas; construção de } \\
\text { pequenos textos; debates e trocas de ideias }\end{array}$ \\
\hline
\end{tabular}

Fonte: Autores (2022)

De acordo com Berbel (2011), as metodologias ativas: "baseiam-se em formas de desenvolver o processo de aprender, utilizando experiências reais ou simuladas, visando às condições de solucionar, com sucesso, desafios advindos das atividades essenciais da prática social, em diferentes contextos" (BERBEL, 2011, p. 29). A proposta da "Aula Leve", compreendida como metodologia de aprendizagem ativa, pretende "oferecer uma didática oposta à expositiva - mas que ainda assim a comporta -, que confira aos alunos o poder de iniciativa em relação ao aprendizado dos conteúdos curriculares" (MENDES, 2012, p. 19). Da maneira como está estruturada, a metodologia pode ser trabalhada nos ambientes de salas de aula da forma como se encontram tradicionalmente organizados e não é necessário nenhum material extra, além daqueles já rotineiramente utilizados na escola. Esta metodologia evita possíveis dificuldades operacionais que docentes e estudantes ressaltam quando algumas metodologias inovadoras passam a ser aplicadas nas escolas. Isso porque, devido a sua flexibilidade, pode ser aplicada a qualquer disciplina e intercalada com as próprias aulas expositivas, pois as quatro etapas que formam esta metodologia estão baseadas na prática das oficinas de estudo: "As quatro etapas permitem leituras do texto em diferentes níveis, estimulando o foco nas principais divisões do conteúdo e o raciocínio sobre o que é o principal” (MENDES, 2012, p. 159).

A autonomia desenvolve-se voluntariamente, por iniciativa e necessidade própria do processo constituído em sala de aula. Como observa Berbel (2011), são promotoras de autonomia atividades em que "haja envolvimento pessoal, baixa pressão e alta flexibilidade em sua execução, e percepção de liberdade psicológica e de escolha" (BERBEL, 2011, p. 27). Berbel reflete sobre a promoção da autonomia e sua relação com a motivação para o aprender em contextos educativos. Pensar a autonomia como dimensão motivadora dos estudantes torna-se estratégia de ação prática com as "aulas leves”. Pporque, desde seu princípio, o método foi criado sobre práticas voltadas ao incentivo, à motivação e ao protagonismo do estudante, tornando-se, assim, uma metodologia ativa de aprendizagem. Esta metodologia não incentiva algo inatingível, pois não é pelo fato de uma metodologia construir as condições para que os estudantes exerçam a autonomia e o protagonismo, que ela deve estabelecer passos altamente 
complexos ou apresentar grandes dificuldades de execução para estudantes e professores. Ao contrário, a presente metodologia revela-se como uma estratégia que trabalha com a própria percepção do estudante como agente, como protagonista de seu próprio (auto) processo de aprendizagem, uma metodologia ativa, como Berbel assinala, que permite que tais condições ocorram na prática da sala de aula:

\begin{abstract}
A implementação dessas metodologias pode vir a favorecer uma motivação autônoma quando incluir o fortalecimento da percepção do aluno de ser origem da própria ação, ao serem apresentadas oportunidades de problematização de situações envolvidas na programação escolar, de escolha de aspectos dos conteúdos de estudo, de caminhos possíveis para o desenvolvimento de respostas ou soluções para os problemas que se apresentam alternativas criativas para a conclusão do estudo ou da pesquisa, entre outras possibilidades (BERBEL, 2011, p. 28).
\end{abstract}

Assim, mais relevante do que estabelecer "o que" fazer é definir "como" fazer. Esta é uma das principais contribuições da "Aula Leve": trabalhar com atividades comuns, mas de forma criativa. Atividades tradicionalmente efetivadas de forma rotineira, desmotivadora e desinteressante, tanto para os estudantes como para os docentes, podem ser trabalhadas de forma criativa, permitindo o protagonismo dos estudantes e a elaboração da competência argumentativa. Necessidade observada por Pezarini e Maciel (2021).

\begin{abstract}
A necessidade de que as práticas educativas nas aulas de Ciências sejam pautadas na competência argumentativa é uma afirmação compartilhada por grande parcela dos docentes dessa disciplina. No entanto essa não é uma realidade vivenciada no âmbito escolar, seja pela carência na formação docente, seja pelos imperativos que impossibilitam tal prática, como é o caso da existência de um currículo engessado. Conduzir os alunos a um processo de construção do pensamento científico é um dos pilares da argumentação, uma vez que, pensamento e linguagem estão intimamente relacionados (PEZARINI e MACIEL, p. 83, 2021).
\end{abstract}

Ressalta-se os destaques dados por Pezarini e Maciel que dificultam o desenvolvimento da competência argumentativa na escola, a carência na formação docente e o currículo engessado. A metodologia ativa "Aula Leve" busca suprir essas duas dificuldades ao ressignificar, na prática das atividades, conteúdos curriculares que seriam ministrados de forma tradicional e trabalhar diretamente com a formação dos docentes, por meio da própria aplicação da metodologia em sala de aula. 


\section{ENCAMINHAMENTO METODOLÓGICO}

A presente análise foi desenvolvida a partir de uma metodologia qualitativa, de caráter exploratório e interpretativo, visto que se pretende conhecer melhor o problema concretamente apresentado a fim de auxiliar a proposição de hipóteses. Como observa Gil, “As pesquisas exploratórias têm como principal finalidade desenvolver, esclarecer e modificar conceitos e ideias, tendo em vista a formulação de problemas mais precisos ou hipóteses pesquisáveis para estudos posteriores" (GIL, 2008, p. 27). Corrobora essa abordagem Flick, quando se refere aos limites da pesquisa qualitativa, afirmando: "a pesquisa qualitativa é orientada para análise de casos concretos em sua particularidade temporal e local, partindo das expressões e atividades das pessoas em seus contextos locais" (FLICK, 2009, p. 28). Partindo desses pressupostos, a pesquisa está organizada em três fases, como apresenta o quadro 2.

Quadro 2 - Fases de organização da pesquisa

\begin{tabular}{|c|c|}
\hline Fase & Atividades \\
\hline $\begin{array}{l}\text { Elaborar um estudo } \\
\text { exploratório por meio de } \\
\text { análise documental que } \\
\text { busca compreender como } \\
\text { é realizada a prática desta } \\
\text { metodologia de } \\
\text { aprendizagem ativa, seus } \\
\text { objetivos, passos, } \\
\text { processos formativos para } \\
\text { docentes e resultados } \\
\text { esperados }\end{array}$ & $\begin{array}{l}\text { i) Documentação atualizada oficial disponível no website do } \\
\text { Programa de Pós-Graduação em Informática na Educação, } \\
\text { vinculado ao Núcleo de Apoio Pedagógico à Educação a } \\
\text { Distância - Produção Multimídia para a Educação, da } \\
\text { Universidade Federal do Rio Grande do Sul: “Aula Leve" } \\
\text { ii) Relatório do Projeto "Aprendizado ativo no cotidiano escolar: } \\
\text { capacitação de professores em oficinas de estudo", realizado em } \\
\text { 2015, pela Secretaria de Estado da Educação do Estado de São } \\
\text { Paulo } \\
\text { iii) “A Nova Sala de Aula”, obra publicada em } 2012 \text { pelo autor } \\
\text { do método }\end{array}$ \\
\hline $\begin{array}{l}\text { Apresentar depoimentos } \\
\text { de docentes e estudantes } \\
\text { que trabalharam com a } \\
\text { oficina de estudos "Aula } \\
\text { Leve" em dois momentos }\end{array}$ & $\begin{array}{l}\text { i) Docentes que praticaram a metodologia em aulas de turmas do } \\
\text { Ensino Fundamental e Médio em escolas do Rio Grande do Sul } \\
\text { ii) Docentes e estudantes que praticaram a metodologia em aulas } \\
\text { do Ensino Fundamental e Médio em escolas de São Paulo }\end{array}$ \\
\hline Avaliação da "Aula Leve" & $\begin{array}{l}\text { Análise contextualizada da Fase } 1 \text { e Fase } 2 \text {, juntamente com a } \\
\text { entrevista com o autor do projeto }\end{array}$ \\
\hline
\end{tabular}
Fonte: Autores (2022)

\section{RESULTADOS E DISCUSSÃO}


De acordo com o percurso metodológico definido serão apresentados os resultados da análise documental, dos depoimentos de estudantes e docentes, da entrevista com o autor do projeto e as discussões propostas.

\section{Análise documental}

A metodologia “Aula Leve" surgiu de uma experiência pessoal. No entanto, sua aplicabilidade já foi testada por centenas de professores e milhares de estudantes de diversas disciplinas e níveis educacionais, evidenciando a autonomia no aprendizado. Em 2012, Mendes publicou "A Nova Sala de Aula", registrando que a aplicação da metodologia, até aquele ano, já tinha acontecido em 113 colégios públicos e privados em 25 municípios do Rio Grande do Sul. A obra traz reflexões sobre essas práticas e depoimentos sobre as experiências adquiridas. O projeto "Aprendizado ativo no cotidiano escolar: capacitação de professores em oficinas de estudo", realizado em 2015, pela Secretaria de Estado da Educação do Estado de São Paulo, aplicou a metodologia em dez escolas da Diretoria de Ensino Região Centro-Oeste da cidade de São Paulo, alcançando 1.102 estudantes de diferentes séries, em 44 turmas e 97 professores. De acordo com a documentação analisada, o método pode ser utilizado paralelamente com as aulas expositivas e possibilitou o aprendizado autônomo por parte dos estudantes. A percepção dos próprios estudantes foi avaliada, ao responderem à questão "Você nota que melhorou seu conhecimento sobre o conteúdo do texto?". Segundo o relatório do projeto: “As respostas revelaram, em todas as escolas, uma taxa extremamente alta (em média 97\%) de alunos que perceberam aprender com base em seu próprio trabalho individual" (SÃO PAULO, 2016, p. 18). O documento ainda declara que as oficinas de estudo podem ser consideradas uma

[...] via segura para introduzir a aprendizagem ativa em salas de aula usuais, visto que "em média $89,9 \%$ dos alunos avaliaram de forma positiva a proposta, com $97,2 \%$ constatando aprendizado e uma rejeição de apenas 0,6\%. Em relação aos professores, 93,8\% avaliaram positivamente a formação (SÃO PAULO, 2016, p. vi).

\section{Depoimentos de docentes e estudantes}

A fim de apresentar um panorama geral das percepções de professores e estudantes que vivenciaram o trabalho com a oficina de estudos "Aula Leve", foram analisados depoimentos disponíveis. Parte desses depoimentos foi selecionada e será 
apresentada a seguir. Para os depoimentos de professores de turmas do Ensino Fundamental e Médio de escolas do Rio Grande do Sul, utilizamos os registros apresentados no website oficial da "Aula Leve", criado e mantido pela NAPEAD Produção Multimídia para a Educação, da Secretaria de Educação a Distância - SEAD, da Universidade Federal do Rio Grande do Sul (UFRGS, 2020). Para os depoimentos de professores e de estudantes de 10 escolas e 44 turmas, contabilizando 1.102 alunos e 97 professores da rede pública estadual da cidade de São Paulo, foi utilizado o relatório do projeto "Aprendizado ativo no cotidiano escolar: capacitação de professores em oficinas de estudo", realizado em 2015 pela Secretaria de Estado da Educação do Estado de São Paulo (SÃO PAULO, 2016). Categorizou-se os relatos para facilitar sua apresentação utilizando, em parte, a categorização elaborada pelo próprio relatório do projeto.

\section{Depoimentos de professores do Ensino Fundamental e Médio de escolas do Rio Grande do Sul}

Foram selecionados alguns depoimentos, a partir das categorizações apresentadas no quadro 3.

Quadro 3: Depoimentos de professores do Ensino Fundamental e Médio de escolas do Rio

Grande do Sul

\begin{tabular}{|c|c|}
\hline Categorização & Depoimento \\
\hline $\begin{array}{lr}\text { Motivação } & \mathrm{e} \\
\text { autonomia } & \text { dos } \\
\text { estudantes } & \end{array}$ & $\begin{array}{l}\text { "Sou prof. a de Matemática e apliquei a oficina. A turma produziu mais } \\
\text { do que em aulas expositivas, pois as tarefas eram simples e divididas } \\
\text { em curtas etapas. A oficina se mostrou ótimo recurso para desenvolver } \\
\text { a autonomia e confiança dos alunos" }(09 / 04 / 2019)\end{array}$ \\
\hline $\begin{array}{l}\text { Simplicidade } \\
\text { objetividade } \\
\text { método }\end{array}$ & $\begin{array}{l}\text { "Oficinas realmente leves, como é proposto nesse projeto. Alunos } \\
\text { participam e aprovaram esse método" (22/03/2019); "Uma ótima } \\
\text { oportunidade de qualificar a prática pedagógica, com materiais básicos } \\
\text { que são utilizados pelos docentes. O diferencial encontra-se na } \\
\text { organização e condução do trabalho" }(25 / 03 / 2019)\end{array}$ \\
\hline $\begin{array}{l}\text { Papel do docente em } \\
\text { sala de aula }\end{array}$ & $\begin{array}{l}\text { Em relação ao papel do docente em sala de aula: "As orientações de } \\
\text { condução da atividade em casos de conversas e desatenções são úteis, } \\
\text { como as outras sugestões. A forma diferenciada de apresentação do } \\
\text { conteúdo é atraente, coloca o docente em movimento, e também o } \\
\text { torna um mediador do conhecimento" (05/02/2019); "A troca com os } \\
\text { alunos foi gratificante pois alguns alunos realizaram as tarefas } \\
\text { propostas com muito entusiasmo." (26/02/2019) }\end{array}$ \\
\hline
\end{tabular}

Fonte: Autores

\section{Depoimentos de estudantes do Ensino Fundamental e Médio de escolas de São Paulo}

Foram selecionados alguns depoimentos, a partir das categorizações apresentadas no quadro 4. 
Quadro 4: Depoimentos de estudantes do Ensino Fundamental e Médio de escolas do São

Paulo

\begin{tabular}{|c|c|}
\hline Categorização & Depoimento \\
\hline Autonomia & $\begin{array}{l}\text { "Eu gostei muito da aula, pois me senti mais capaz de aprender as } \\
\text { coisas" ( } 2^{\circ} \mathrm{EM}, \text { EE Odair Mandela) } \\
\text { "Acho que deveria ter mais aulas do tipo, até para acreditarmos no } \\
\left.\text { nosso potencial" ( } 9^{\circ} \mathrm{EF} \text {, EE Lourival Machado }\right) \\
\text { "Parei para pensar que realmente consigo aprender qualquer coisa!" } \\
\left(8^{\circ} \mathrm{EF}, \text { EE Maria Ribeiro) }\right. \\
\text { "Não sabia que tinha tanta capacidade. Obrigada!" }\left(2^{\circ} \mathrm{EM}, \mathrm{EE} \text { Adolfo }\right. \\
\text { Gordo) }\end{array}$ \\
\hline $\begin{array}{l}\text { Autoestima e } \\
\text { confiança pessoal }\end{array}$ & $\begin{array}{l}\text { "Muito boa a atividade, a partir dela, notamos melhor que os } \\
\text { responsáveis do nosso conhecimento somos nós mesmos" ( } 2^{\circ} \mathrm{EM}, \mathrm{EE} \\
\text { Alexandre Von Humboldt) } \\
\text { "A aula me ensinou mais do que qualquer outra sobre o tema, e o } \\
\text { melhor é que fomos nós mesmos que desenvolvemos a atividade" ( } 2^{\circ} \\
\text { EM, EE Alberto Torres) } \\
\text { "Foi ótimo, como se nós tivéssemos dado uma aula para nós mesmos!" } \\
\text { (6 } 6^{\circ} \mathrm{EF}, \text { EE Oswaldo Aranha) }\end{array}$ \\
\hline Atividades e método & $\begin{array}{l}\text { "A escola deveria ensinar assim" }\left(2^{\circ} \mathrm{EM}, \text { EE Alberto Torres }\right) \\
\text { "Achei interessante, porque em pouco tempo eu aprendi bastante } \\
\text { coisa e houve silêncio e foco na matéria até. Todo mundo deveria ser } \\
\text { assim, todas as aulas" ( } 2^{\circ} \mathrm{EM} \text {, EE Alberto Torres) }\end{array}$ \\
\hline $\begin{array}{l}\text { Utilidade do método } \\
\text { para sua vida pessoal } \\
\text { e estudos caseiros }\end{array}$ & $\begin{array}{l}\text { "Este tipo de aula me ajudará a ter conhecimento melhor de coisas } \\
\text { que eu não sei e ajudará futuramente" }\left(2^{\circ} \mathrm{EM} \text {, EE Odair Mandela) }\right. \\
\text { "Foi muito legal. Essa aula ajudou muito na minha vida" ( } 9^{\circ} \mathrm{EF}, \mathrm{EE} \\
\text { Lourival Machado) } \\
\text { "Eu gostei, assim com essa forma podemos estudar em casa" }\left(2^{\circ} \mathrm{EM} \text {, }\right. \\
\text { EE Alberto Torres })\end{array}$ \\
\hline
\end{tabular}

Fonte: Autores

\section{Depoimentos de professores do Ensino Fundamental e Médio de escolas de São Paulo}

Foram selecionados alguns depoimentos, a partir das categorizações apresentadas no quadro 5.

Quadro 5: Depoimentos de professores do Ensino Fundamental e Médio de escolas do São

$$
\text { Paulo }
$$

\begin{tabular}{|l|l|}
\hline Categorização & \multicolumn{1}{c|}{ Depoimento } \\
\hline Motivação e & "Muito interessante. Boa proposta para facilitar o dia a dia do professor e \\
autonomia dos & para ajudar o aprendizado do aluno. Desenvolve a autonomia do aluno e \\
estudantes & $\begin{array}{l}\text { põe o professor como mediador. Parabéns!" (EE Alberto Torres) } \\
\text { "Trabalho diferenciado, com objetivos claros e atingiu 100\% a } \\
\text { aprendizagem dos alunos, despertou o aluno para sua autonomia" (EE } \\
\text { Daniel Pontes) }\end{array}$ \\
\hline
\end{tabular}




\begin{tabular}{|l|l|}
\hline $\begin{array}{l}\text { Simplicidade e } \\
\text { objetividade do } \\
\text { método }\end{array}$ & $\begin{array}{l}\text { "Metodologia interessante, a qual me causou surpresa com relação ao } \\
\text { sucesso obtido em meio aos alunos. Pretendo utilizá-la" (EE Guiomar } \\
\text { Rinaldi) } \\
\text { "Achei muito interessante, pois esse método fez com que eu refletisse a } \\
\text { respeito de nossa prática e trata-se de algo simples que pode ser aplicado } \\
\text { em todas as disciplinas e em qualquer lugar. Gostei muito do trabalho e } \\
\text { das nossas reflexões/discussões" (EE Maria Ribeiro) }\end{array}$ \\
\hline $\begin{array}{l}\text { Papel do } \\
\text { docente em sala } \\
\text { de aula }\end{array}$ & $\begin{array}{l}\text { "Achei que a condução da formação levou em conta toda a situação dos } \\
\text { sistemas educacionais o que é extremamente importante. Além disso, } \\
\text { trazer PRÁTICAS deixa claras as alternativas possíveis para mudar o } \\
\text { cenário atual" (EE Maria Ribeiro) }\end{array}$ \\
\hline $\begin{array}{l}\text { Apoio dos } \\
\text { docentes }\end{array}$ & $\begin{array}{l}\text { "A atividade foi pertinente e válida para ser aplicada em sala de aula" (EE } \\
\text { Alberto Torres) } \\
\text { "É um método novo, que pode nos auxiliar no desenvolvimento das aulas" } \\
\text { (EE Alberto Torres) } \\
\text { "Muito interessante. Aula dialógica e intuitiva" (EE Oswaldo Aranha) }\end{array}$ \\
\hline
\end{tabular}
Fonte: Autores

\section{Entrevista}

A partir da entrevista com Fábio Mendes, relacionou-se as reflexões apresentadas com aspectos da análise documental e dos depoimentos de estudantes e professores que passaram pela experiência da metodologia. Como Mendes destaca, para desenvolverem autonomia, "Os alunos precisam ser instruídos a como fazer escolhas em relação ao seu aprendizado, criando, cada um, ao final, seu próprio modo de aprender" (MENDES, 2012, p.116). A cada etapa da metodologia é imprescindível que o estudante decida, de forma autônoma, qual trecho do texto marcar, quais palavras-chave selecionar e que anotações produzir, tendo a confiança do docente na autonomia dos estudantes. "Muitas vezes, o professor desconfia da capacidade do estudante”. Mas a oficina de estudos, ao mesmo tempo, demonstra para o aluno que ele é capaz e o professor percebe e se surpreende com a capacidade do "estudante" (MENDES, 2020, informação verbal). Portanto, a aplicação da metodologia depende da compreensão do docente em relação ao seu papel em sala de aula. Um desafio que o próprio docente é convidado a superar, antes mesmo da efetivação das práticas em sala de aula. Por isso, Mendes ressalta que a maior parte das críticas ao método é apresentada pelos docentes antes de sua aplicação em sala de aula: “As críticas são, em sua maioria, questões práticas pontuais, como se a escola permite fazer cópias de textos ou como o professor pode incluir esta oficina de estudos dentro de seu planejamento" (MENDES, 2020, informação verbal). A falta de conhecimento sobre a prática em sala de aula traz uma apreensão compreensível, mas a experiência pode e deve ser realizada, pois praticamente não tem custo, não envolve necessariamente o uso de tecnologias digitais e a simplicidade do método facilita sua 
aplicação: "Tem um modo de fazer o atendimento aos estudantes, tem um modo de fazer a movimentação. E, no final das contas, acaba sendo uma aula muito mais leve do que ficar falando sobre um conteúdo” (MENDES, 2020, informação verbal).

As condições para a autonomia, a autoria, a autodisciplina e a autoconfiança devem ser construídas conjuntamente pelos docentes e estudantes em sala de aula. $\mathrm{O}$ professor deve acreditar que o estudante é capaz, deve deixar o estudante tentar: " $O$ professor deve abrir espaço para que os estudantes descubram a capacidade que eles têm. Eles não têm como descobrir suas capacidades, se eles não têm espaço para isso" (MENDES, 2020, informação verbal). Como Mendes enfatiza, "são muitos autos" (MENDES, 2020, informação verbal) que podem ser desenvolvidos, mas sempre respeitando as diferentes formas de aprendizado dos estudantes, ao mesmo tempo em que o docente deve acreditar em sua própria capacidade de ministrar uma aula diferente. Assim, esta metodologia configura-se como um desafio em relação a certos padrões tradicionais de transmissão de conteúdos. Os desafios são superados pelos estudantes durante as atividades, o que permite que exercitem na prática a autonomia e a autoria ao tomarem decisões com confiança e iniciativa sobre o que estão estudando e aprendendo.

\section{CONSIDERAÇÕES FINAIS}

Este artigo analisou uma metodologia ativa de aprendizagem, a oficina de estudos conhecida como "Aula Leve", a fim de verificar se poderia contribuir para o desenvolvimento da autonomia e da autoria dos estudantes em sala de aula, partindo de estratégias de ensino e de aprendizagem direcionadas às práticas da leitura, interpretação e produção textual. A partir dos resultados desta pesquisa, constatou-se que os docentes reconhecem que a metodologia é de fácil aplicação e contribui para a participação e produção dos estudantes em aula. Já os estudantes percebem sua capacidade de aprender sozinhos (autonomia no aprendizado), de interpretar textos, de tomar decisões e de produzir reflexões e anotações próprias (autoria). O fato de os sujeitos exercerem a autonomia e a autoria em sala de aula permite considerar que esse aprendizado incorporado por esses sujeitos possa ser exercido para além do espaço da sala de aula. Isso porque há a construção das condições para que os estudantes possam exercer suas escolhas de forma autônoma, em relação ao seu próprio aprendizado - autoaprendizado. Trata-se de uma estratégia que está de acordo com a proposta estabelecida por Freire, no 
sentido de que a autonomia deve perpassar todo o processo educacional, de modo que o aprendente possa encontrar seu protagonismo de aprender a aprender e aprender a ser. Nesse sentido, compreende-se que, mesmo sem exigir grandes recursos ou desconsiderar o trabalho já realizado pelos professores, a aplicação da "Aula Leve" contribui para estimular e efetivar práticas focadas no processo de aprendizagem dos estudantes, fortalecendo a autonomia, a autoria, a autodisciplina e a autoconfiança dos estudantes.

\section{REFERÊNCIAS}

ANTUNES, J; NASCIMENTO, V. S; QUEIROZ, Z. F. Metodologias ativas na educação: problemas, projetos e cooperação na realidade educativa. Informática na Educação: teoria \& prática, Porto Alegre, v. 22, n. 1, p. 111-127, jan./abr. 2019. Disponível em: https://seer.ufrgs.br/InfEducTeoriaPratica/article/view/88792. Acesso em: 6 jul. 2020.

BERBEL, N. A. N. As Metodologias ativas e a promoção da autonomia de estudantes. Semina: Ciências Sociais e Humanas, Londrina, v. 32, n. 1, p. 25-40, jan./jun. 2011. Disponível em:

http://www.uel.br/revistas/uel/index.php/seminasoc/article/view/10326/0. Acesso em: 6 jul. 2020.

BRASIL. Ministério da Educação. Base Nacional Comum Curricular. Brasília, DF: Ministério da Educação, 2017. 595 p. Disponível em:

http://basenacionalcomum.mec.gov.br/images/BNCC_EI_EF_110518_versaofinal_site. pdf. Acesso em: 6 jul. 2020.

BRASIL. Ministério da Educação. Secretaria de Educação Básica. Diretoria de Currículos e Educação Integral. Diretrizes Curriculares Nacionais Gerais da Educação Básica. Brasília, DF: MEC, SEB, DICEI, 2013. 562 p. Disponível em: http://portal.mec.gov.br/index.php?option=com_docman\&view $=$ download\&alias $=1554$ 8-d-c-n-educacao-basica-nova-pdf\&Itemid=30192 Acesso em: 6 jul. 2020.

CHAUÍ, M. Introdução à história da filosofia: dos pré-socráticos a Aristóteles, volume I. São Paulo: Companhia das Letras, 2002.

FLICK, U. Qualidade na pesquisa qualitativa. Porto Alegre: Artmed, 2009.

FREIRE, P. A importância do ato de ler: em três artigos que se complementam. São Paulo: Cortez, 1998.

Pedagogia da Autonomia: saberes necessários à prática educativa. Rio de Janeiro: Paz e terra, 2019. 1997.

Professora sim, tia não: cartas a quem ousa ensinar. São Paulo: Olho d'água, 
GIL, A. C. Métodos e técnicas de pesquisa social. São Paulo: Atlas, 2008.

MENDES, F. R. A Nova Sala de Aula. Porto Alegre: Autonomia, 2012.

MENDES, F. R. Aula Leve: entrevista [mar. 2020]. Entrevistadores: Enrique Sérgio Blanco, Larissa Liss Andrade e Maria dos Remédios Lima Silva. Porto Alegre: [s. n.], 2020. 2 arquivos mp3(52min). Entrevista concedida especialmente para elaboração deste artigo.

MENDES, F. C. R; CARVALHO, M. J. S. Desenvolvimento de aplicativo AulaLeve para formação de professores em uma metodologia de aprendizagem ativa. In: Simpósio Brasileiro de Informática na Educação, 30., 2019, Brasília, DF, Anais [...], Brasília, DF,: Sociedade Brasileira de Computação, 2019. p. 319-328. Disponível em: https://br-ie.org/pub/index.php/sbie/article/view/8736]. Acesso em: 6 jul. 2020.

ORLANDI, E. L. P. Interpretação: autoria, leitura e efeitos do trabalho simbólico. Campinas, SP: Pontes Editores: 2007.

PEZARINI, A, R; MACIEL, M. D. Argumentação no ensino de ciências por intermédio de um modelo didático misto: um produto educacional. REPPE: Revista do Programa de Pós-Graduação em Ensino - Universidade Estadual do Norte do Paraná Cornélio Procópio, v. 5, n. 1, p. 79-108, 2021. Disponível em: https://www.ufrgs.br/aulaleve/. Acesso em: 16 ago. 2021.

SÃO PAULO (Estado). Secretaria de Estado da Educação Diretoria de Ensino Região Centro Centro-Oeste. Relatório: Projeto Aprendizado Ativo no Cotidiano Escolar Capacitação de Professores em Oficinas de Estudo. São Paulo: Secretaria de Estado da Educação, 2016. Disponível em: http://s3.amazonaws.com/porvir-prod/wpcontent/uploads/2017/01/18135003/RELATO\%CC\%81RIO-Projeto-Oficinas-deEstudo-SP-Jane.pdf Acesso em: 6 jul. 2020.

TRIVIÑOS, A. N. S. Introdução à pesquisa em ciências sociais: a pesquisa qualitativa em educação: o positivismo, a fenomenologia, o marxismo. São Paulo: Atlas, 1987.

UNIVERSIDADE FEDERAL DO RIO GRANDE DO SUL. Aula leve: formação gratuita em oficinas de estudo, uma didática alternativa à aula expositiva e que ensina a estudar. [Porto Alegre: UFRGS]. Disponível em: https://www.ufrgs.br/aulaleve/. Acesso em: 6 jul. 2020.

ZATTI, V . Autonomia e educação em Immanuel Kant e Paulo Freire. Porto Alegre: EDIPUCRS, 2007.

Recebido em: 20/01/2022

Aprovado em: 21/02/2022

Publicado em: 25/02/2022 